\title{
MODELING THE DECAY IN AN HBIM STARTING FROM 3D POINT CLOUDS. A FOLLOWED APPROACH FOR CULTURAL HERITAGE KNOWLEDGE
}

\author{
F. Chiabrando a, M. Lo Turco a , F. Rinaudo ${ }^{\text {a* }}$ \\ ${ }^{a}$ Department of Architecture and Design, Politecnico di Torino, viale Mattioli n.39 10125, Torino, Italy - \\ (filiberto.chiabrando,massimiliano.loturco,fulvio.rinaudo)@ polito.it
}

KEY WORDS: Terrestrial Laser Scanner, Structure from Motion, point cloud, Heritage BIM, semantic modelling, decay

\begin{abstract}
:
The recent trends in architectural data management imply the scientific and professional collaborations of several disciplines involved in the design, restoration and maintenance. It seems an achieved concept that, in the next future, all the information connected to new interventions or conservation activities on historical buildings will be managed by using a BIM platform. Nowadays the actual range or image based metric survey techniques (mainly produced by using Terrestrial Laser Scanner or photogrammetric platform today more based on projective geometry) allow to generate 3D point clouds, 3D models, orthophotos and other outputs with assessed accuracy. The subsequent conversion of 3D information into parametric components, especially in an historical environment, is not easy and has a lot of open issues. According to the actual BIM commercial software and to the embedded tools or plugin, the paper deals with the methodology followed for the realization of two parametric 3D models (Palazzo Sarmatoris and Smistamento RoundHouse, two historical building in the north-west part of Italy). The paper describes the proposed workflow according to the employed plug-in for automatic reconstruction and to the solution adopted for the well-known problems connected to the modeling phase such as the vaults realization or the 3D irregular surfaces modeling. Finally, the studied strategy for mapping the decay in a BIM environment and the connected results with the conclusions and future perspectives are critically discussed.
\end{abstract}

\section{INTRODUCTION}

According to the continuous progress in the Cultural Heritage knowledge and documentation connected to the actual survey techniques and instruments, nowadays the realization of 3D models oriented to the historical structures could be considered a standard procedure never under discussion. In this scenario, the achieved metric deliverables play an important and crucial role for the monitoring of the buildings especially if the objects are under restoration analysis and/or projects. The availability of 3D data and connected products produce, as a result, an increasing interest in instruments and methods able to manage those information and digital data in a unique tool. The Building Information Modeling (BIM) is certainly one of the most reliable methods to manage architectural design and building processes. Moreover, today it is considered the best process to collect and link together different data sources with a unique $3 \mathrm{D}$ parametric model. One of the most meaningful definitions of Building Information Modeling, mentioned on international standards, confirms that it is a shared digital representation of physical and functional characteristics of any built object, which forms a reliable basis for decision-making process (ISO,2010). Nowadays, the use of BIM approach for historical architecture is still considered a great challenge and it is considered one of the most interesting research issue able link together several disciplines such as Geomatics, Drawing and Representation, Restoration, History, etc. The work here described is the outcome of some shared and multidisciplinary activities carried out by a group of researchers of the Politecnico di Torino.

The paper deals with the methodology followed for the realization of two parametric HBIM models. The first: Palazzo Sarmatoris (Figure 1, above) is a Sixteenth-century building located in Salmour, a small town near Cuneo in Piedmont. The second is the Smistamento Roundhouse, a building of the Italian railway society (Ferrovie dello Stato) used in the past as a storage area of locomotives located in Torino (Figure 1, below).

The artifacts are very different from each other. Nevertheless, from the operative point of view, there are some main common elements of interest.

Mentioning the principal ones: the integration of different survey and measurement techniques; the verification of the real achieved Level of Accuracy; the creation of parametric components not available in the commercial platform libraries; the need of innovative methods for the mapping of decays, by linking together the graphic and alphanumeric systems in a unique BIM environment.
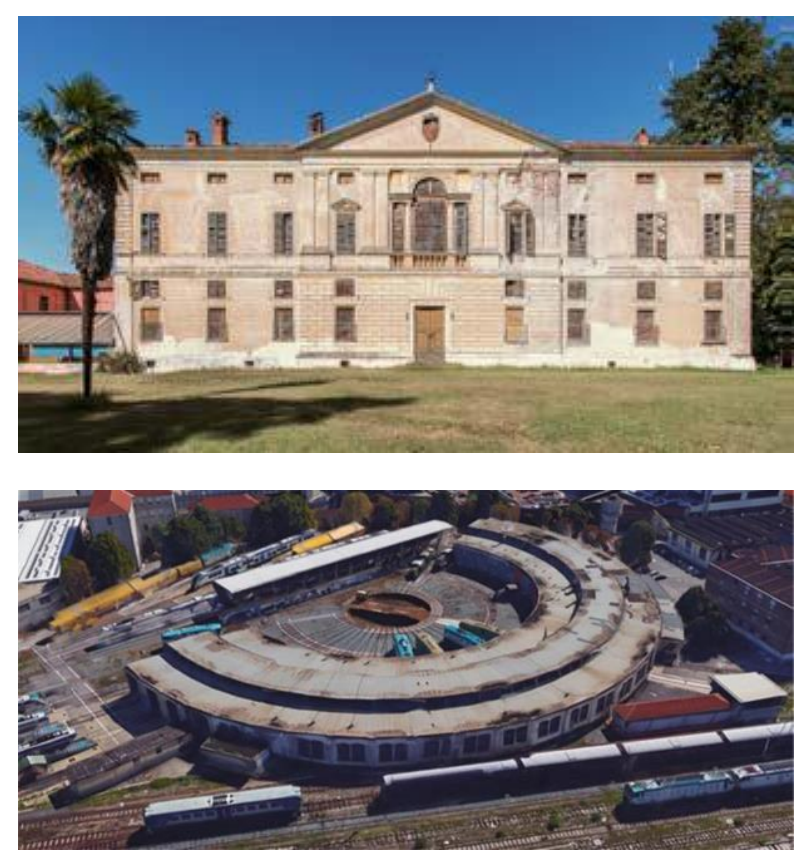

Figure 1. Palazzo Sarmatoris (above) and the Smistamento Roundhouse (below). 
This final aim has been scarcely investigated by the Scientific Community by now.

This paper is organized as follows: Section 2 will be dedicated both to the analysis of the state-of-the-art of integrated metric survey techniques used for $3 \mathrm{D}$ modeling reconstruction, taking into account both the advantages and the disadvantages. Section 3 describes the case study, the survey and the modeling technique, while the following Section 4 describes the relationship between BIM and restoration with a specific regard to the modeling of the decays. Section 5 is dedicated to the conclusions and final considerations.

\section{STATE OF-THE-ART: FROM BIM TO HBIM. ADVANTAGES AND CRITICALITIES}

For several years, most countries in Northern Europe have widely implemented BIM methodology, particularly in the domain of new constructions. Several papers deal with the description of the methodologies, processing steps and standards on different case studies in the field of BIM (Eastman et al., 2011). Large activities on BIM implementation have been developed in foreign Countries such as United Kingdom (BSC, 2013; AEC, 2012), Finland (Building smart Finland, 2012), and Norway (Statsbygg, 2013).

The development of this emerging approach is slower in the South of Europe: only in the last years, a large activity around this topic is going to affirm the increasing interest on the BIM processes. In Italy (Country deeply characterized by existing historical buildings and historical contexts), BIM is becoming a very important topic. We are assisting to an increasing development of HBIM (Historical Building Information Modeling), defined by the scientific literature as the most interesting method to define a semantic aware $3 \mathrm{D}$ reconstruction of historical elements, regardless the needs, the aims and the uses of a 3D model based on parametric approach. The modelling and monitoring phases have been analyzed by several authors: (Barazzetti et al., 2015a; Dore et al., 2015; Baik et al., 2014; Oreni, 2014; Ludwig et al., 2013, Miller et al., 2014, Volk et al., 2014; Barazzetti et al., 2015b; Quattrini et al, 2015; Barazzetti et al., 2014; Lin, 2014, Apollonio et. al, 2012; Donato et., al 2017; Castagnetti et al., 2017).

HBIM was developed in the last ten years (Murphy et al, 2009) like a new prototype-system of BIM, a modelling of historic structures as parametric objects in a database "library". These objects can be collected and modelled using a reverse engineering process, creating full 2D and 3D models including details behind the object's surface, concerning its methods of construction and material makeup. Information are taken on the base of 3D reality-based data from point clouds, by automatic or semi-automatic recognition (Murphy et al, 2012).

The chance to combine a high level of different information in a unique and shared database allows figuring out the next spread of the HBIM adoption as a standard instrument for all the decisionmaking processes related to the Cultural Heritage domain. Beside the geometric 3D information, it is possible to define all the alphanumeric information of an historical complex. The main important are: stratigraphy, decay analysis, structural information, material composition, technological features, previous survey/interventions, old and recent pictures, historical documents, etc. The different category of information are hierarchically organized, and, creating a full-integrated survey, can be used and managed for several aims.

According to these assumptions, HBIM could be defined as a semantic-aware database connected to the historic buildings, in which the geometric model need to be join to descriptive information multi-source (Quattrini et al, 2015). Therefore, it is necessary to start from a correct survey to correctly define the architectural shapes. Actually, the most used strategy is based on the point clouds obtained from range base (LiDAR, SLAM etc) or image-based techniques (SfM, photogrammetry). Moreover, Geomatics techniques allow to easily generate 3D models, orthophotos and other outputs with assessed accuracy.

The subsequent conversion of 3D information into parametric components, especially in an historical background, is very timeconsuming and has several open issues (Lo Turco, Sanna, 2010). According to the geometric rules defined by historical treatises and/or the normal practice of the past, the architectural shapes have to be recognized and segmented from the raw 3D data to be embedded in the HBIM: surfaces (planes, curves, or extrusion), volumes and complex objects. This conversion could be based on:

- manual modelling operations of volumes and shape fromscratch;

- semi-automatic procedures, by managing cross sections and surface extrusions;

- automatic procedures, to rebuild the object according to automatic surface extraction from the point cloud.

The gap between the transformations of a point cloud into a parametric model is today a bottleneck into HBIM adoption because of very heterogeneous geometries: most of them need to be manually re-modelled because no automatic recognition can be used for the great metric discrepancy between real objects and virtual reconstructions. Within this scenario different strategies and approaches were developed in the last years, thanks both to internal tools linked to the BIM software or external software that are useful to simplify the BIM modelling phase.

Regarding the application of BIM to restoration interventions, the attention was focused on the chance to model degradations in the BIM platform, enriching the related database with graphic, geometric and alphanumeric data that can be effectively used to design and manage future interventions. In the next sections a complete description of the achieved results is widely explained, with a final focus on the proposed approach followed for the graphic representation of pathologies. This issue is very complex to be managed within the HBIM environment; it was proposed to use an adaptive component, a specific object that can be adapted to a surface using movable vertex. This flexible geometry could be associated with flat and curved surfaces as well. This is considered by the authors as one the most innovative part of the entire work, because no instances related to these themes were found (Lo Turco et al., 2017).

\section{THE CASE STUDIES: PALAZZO SARMATORIS AND TORINO SMISTAMENTO ROUNDHOUSE}

Two different tests are here presented: the first, Palazzo Sarmatoris, a historic complex dated back to the XVII century. The second, Smistamento Roundhouse in Torino a historical industrial building erected at the beginning of the XX Century. Below, some information related to the buildings, then the description of surveys methodologies and the strategy employed for the HBIM realization are reported in order to obtain a final product that could be a useful instrument for documenting and improve the knowledge of the analyzed artifacts.

\subsection{Historical background}

The area of Palazzo Sarmatoris was reported in the Theatrum Sabaudiae as Palatium Sarmatoris (Figure 2, Roccia, 2000). The building is located in Salmour, a little village close to Fossano in the Cuneo province. Despite the important historic interest, the Palazzo Sarmatoris is abandoned; and because of that, several thefts of the historical furniture occurred in the last years. 
Nowadays, according to the lack of ordinary maintenance the structures, the external and internal walls present several problems and decays: without an important restoration project and the connected retrofit works probably the structure will suffer important damages and significant breaks in the next future.

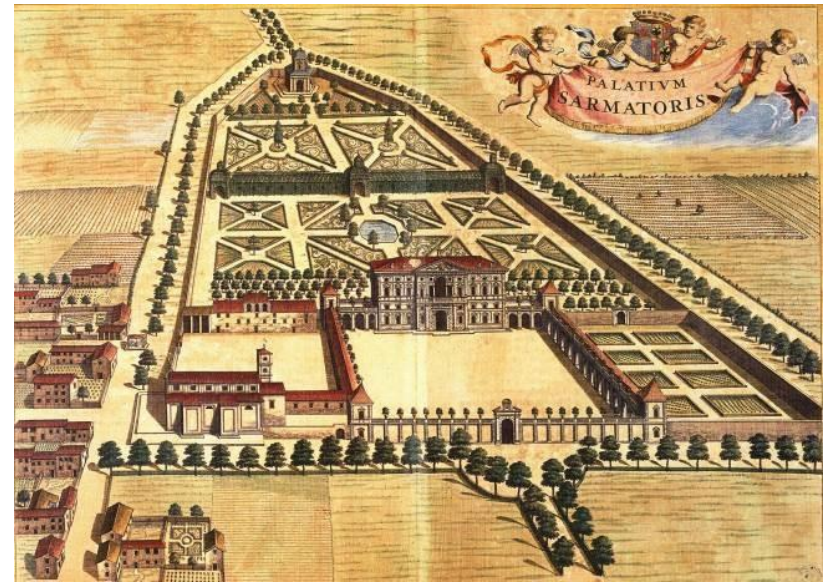

Figure 2. A view of the Palazzo Sarmatoris in the Theatrum Sabaudiae (Roccia, 2000).

The second building is a property of the Ferrovie dello Stato, now abandoned and originally used for the storage of locomotives; during the last years, a specific intervention has been proposed. The building was built to adapt the railways for the Universal Exhibition of 1911, to celebrate the 50th anniversary of the establishment of the Unification of Italy.

The maintenance area was constituted by a roundhouse containing 51 shelter railroad tracks next to two sheds for the most complex interventions (A and B parts, Fig. 3). The bombings of 1943 caused huge damages to the circular structure, knocking down some of the 51 aisles, reducing the overall number to 32 .

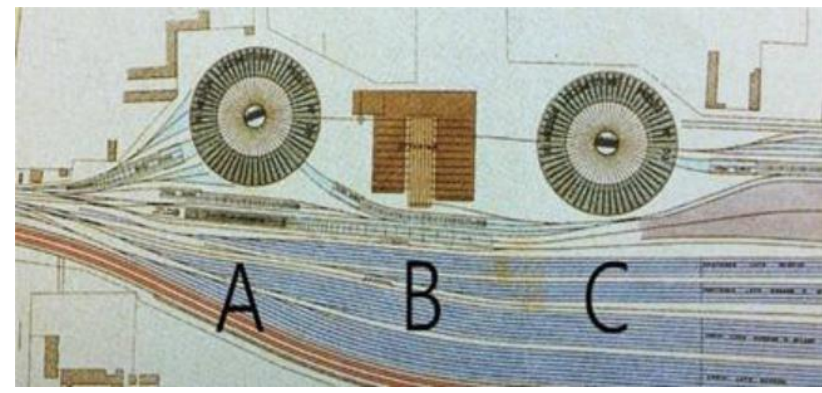

Figure 3. Detail of the site plan, developed in 1905.

\subsection{D metric survey}

In order to realize a parametric model in a HBIM environment the objective of the survey need to be the realization of a complete $3 \mathrm{D}$ point cloud of the analyzed objects. The surveys operations have been carried out by using the image base approach (photogrammetry) for the Palazzo Sarmatoris and TLS techniques for the metric survey of the Smistamento Roundhouse.

In the first case a complete photogrammetric survey has been achieved using terrestrial and UAV images (oblique and nadir images), in the external part and in the main internal rooms (the other rooms were surveyed by manual measurements integrated by preexisting drawings). In the second case, by considering the evident symmetry of the building and the accuracy requirement of the survey a complete external survey has been done and only one module of the structure was also surveyed indoor by using TLS instruments.

In both cases, a first order control network has been realized by using GNSS and/or Total Station survey, while the GCPs needed for image orientation and TLS point clouds registration were measured by using a Total Station connected to the existing first order control networks.

The Palazzo Sarmatoris façades and the roof of the ancient Palace were acquired by means of a COTS (Commercial Off The Shelf) UAV system able to acquire nadir and oblique images as well. Moreover, in order to improve the level of detail for better documenting the lower parts of the façades and the main internal room, the UAV data were integrated with close-range image acquisition.

The well-known Phantom 4 produced by DJI acquired the aerial data. The flight plans were realized at an elevation of about $15 \mathrm{~m}$ over the ground level in order to have a GSD (Ground Sampling Distance) of about $4 \mathrm{~mm}$. Finally, a nadir (3 strips) and oblique acquisition (around the Palace with the camera oriented at $45^{\circ}$ ) have been realized for better documenting the area (Figure 4).
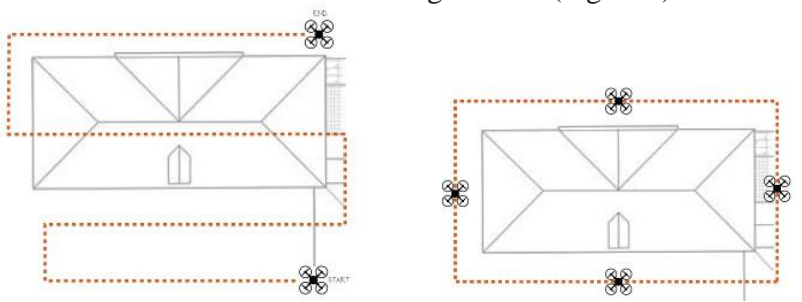

Figure 4. Scheme of the UAV acquisition (nadir stripes left, oblique acquisition route right) of Palazzo Sarmatoris

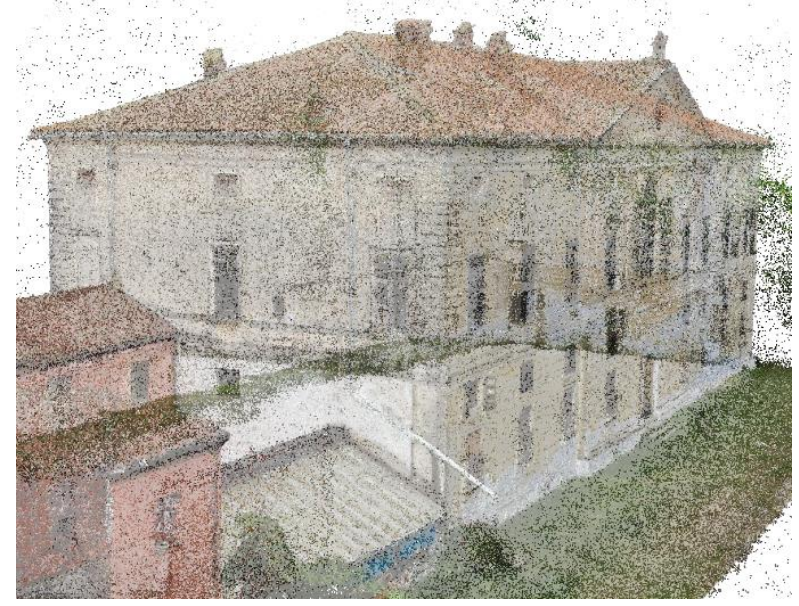

Figure 5. The Achieved point cloud obtained using UA Vand terrestrial data in the external part of Palazzo Sarmatoris.

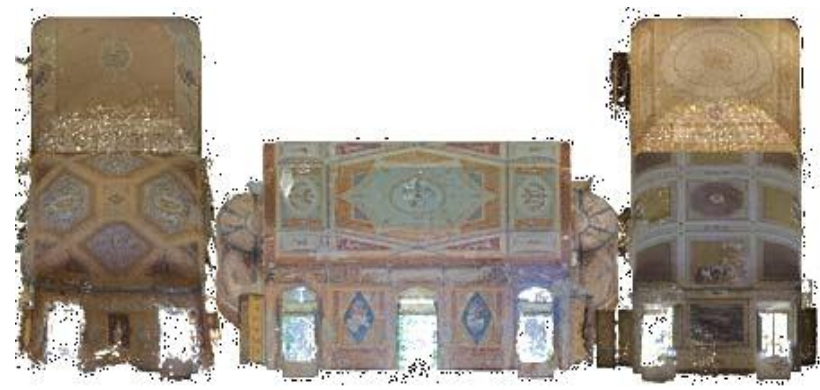

Figure 6. Point clouds of the five main room in the lower floor. of Palazzo Sarmatoris . 
The terrestrial acquisitions were recorded using a Nikon 5D full frame digital camera equipped with a lens of focal length $17 \mathrm{~mm}$. In the external part the shooting distance was about $4 \mathrm{~m}$ with as a result a GSD of about $2 \mathrm{~mm}$. The data were processed using Agisoft Photoscan combining the different dataset using the common reference system measured with traditional topographic survey operations. The mean RMS measured on several Check Points $(\mathrm{CP})$ in the internal and external part was less than $1 \mathrm{~cm}$. In the following figures a view of the realized point clouds of the external part (Figure 5) and in the main internal rooms (Figure 6) of Palazzo Sarmatoris are presented.

The Smistamento Roundhouse was surveyed using a TLS, following the typical approach for architectural heritage (Axelsson, 1999; Vosselman, \& Maas, 2010). A Faro Focus 3D was employed for acquiring the complete area. All the building was recorded in the external part with a quality of $1 / 5$ that according to the typical settings of the Faro scanner means one point each $8 \mathrm{~mm}$ at $10 \mathrm{~m}$. Only two internal parts were surveyed with the laser because the structural symmetry was judge enough to allow the accuracy requirement satisfaction.

After the acquisition, all the scans were colored, filtered, registered and referenced according to the first order control network previously realized.

Figure 7 shows a view of the complete point cloud with the first order control network measured with GNSS and Total Station measurements.
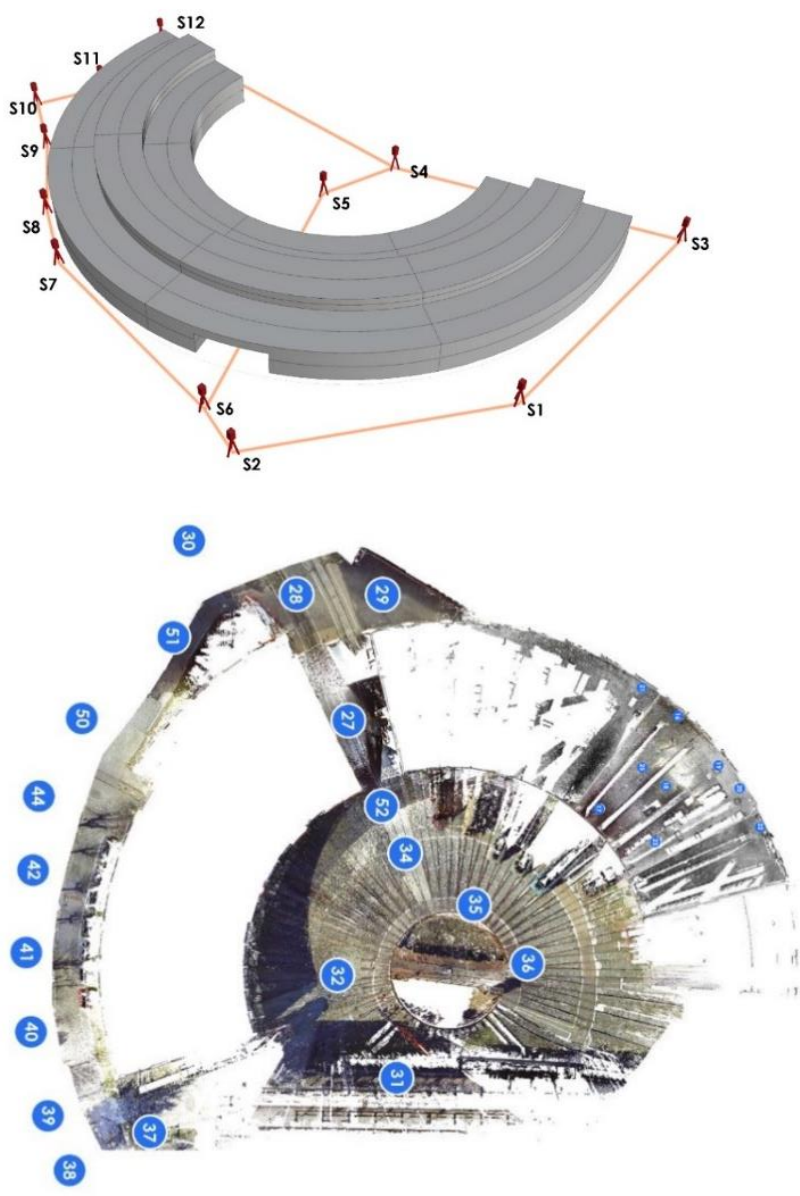

Figure 7. First order control network (above) and the registered point clouds (below)

The result of the registration phase, performed by using the cloud to cloud approach (Iterative Closest Points) and furthermore using the Ground Control Points for georeferencing the products has been checked on some CP. The mean obtained RMS was under $2 \mathrm{~cm}$.

\subsection{From the point cloud to the parametric model}

Once the survey is completed the next step refers to the realization of the parametric model. In this context, the realization of the model in a BIM environment is connected to the creation of objects that represent building components, including both geometric and non-geometric attributes and relationships. In the analyzed case studies, the model is created on the basis of previously captured information. The previous phase connected to data capture, processing and recognition methods influences the quality through the deployed technique and the provided Level Of Development (meant as the degree of data reliability associated with different elements). Actually, another issue refers to the Level of Graphic Detail, (that defines the Level of GRAphic DEtail - GRADE- of drawings). The first classification was provided according to the American Institute of Architects (AIA) that have defined the standardized protocol of LOD in BIM. Actually, we could divide this formal language in five levels of development: LoD 100 (elementary representation); LoD 200 (generic models); LoD $300+350$ (executive planning); LoD 400 (construction planning); LoD 500 (as-built). (BIM FORUM, Level of Development Specifcation, 30 October, 2015).

On the other hand the level of Graphic Detail (Grade), which should be strictly related to the aims of the model and to the level of accuracy of the metric survey (Fai et al., 2014; Lo Turco et al., 2016; Chiabrando et al., 2017). From a purely graphic point of view, the resolution degrees of the identified models can be divided into (Figure 7):

- Grade 1: coarse, a three-dimensional processing with minimum possible detail, consistent to 1:200 scale;

- Grade 2: medium, a three-dimensional model with a good detail level, such to identify its topological, formal, and dimensional characteristics, and partly also its metric characteristics, consistent to 1:100 scale;

- Grade 3: fine, a three-dimensional model equal to the one in Grade 2 in terms of technical and informative aspects, but with much more accurate graphic features, with a photorealistic representation, consistent to 1:50 scale.

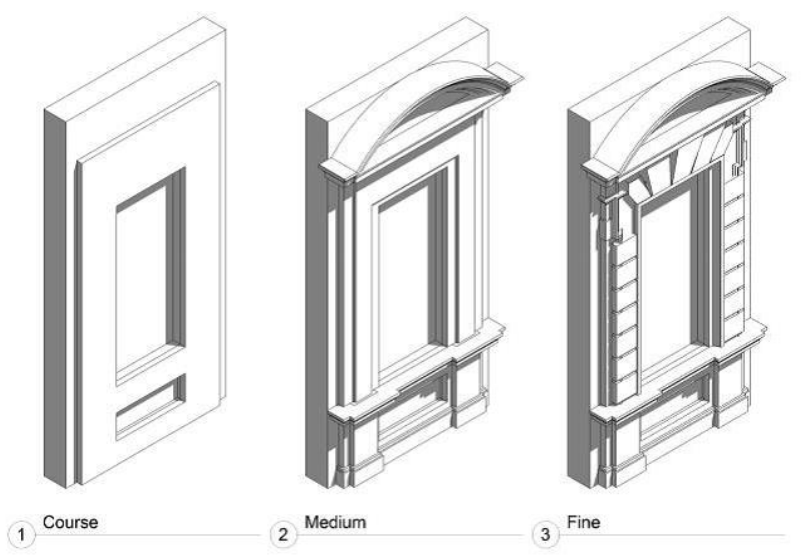

Figure 8. 3D modelling of the same building component according to several GRAphic DEtails (GRADe).

According to the survey data and to the obtained accuracy after the processing, the modelling strategy was oriented to the realization of a final $3 \mathrm{D}$ representation suitable for a scale 1:50$1: 100$. 
As said, three main strategy were explored for the realization of the parametric model. Manual modelling starting from scratch in order to rebuild the volumes and the real shape; semi-automatic method, fitting the primitives to the point clouds, using the cross section for modelling or making surface extrusion, and finally a more automatic approach that allows to rebuild the object according to automatic surface extraction from the point cloud. For HBIM purpose, the automatic approach is not suitable since is hardly to describe the shape of historical buildings using simple geometries. According to this assumption, several plug-in are under development: points-to-BIM, scan-to-BIM, Recaptureand, PointSense, PointCab4 Revit or PointCab4BIM are probably nowadays the most common used in the scientific and professional communities. The aim of those plug-ins consists in the creation of parametric object from metric data processing, through the point cloud management.

In the present work PointSense for Revit was mainly used: it is a Kubit plug-in resold by Faro that allows the user to import the whole point cloud or a part of it directly into Revit family editor. Moreover, PointSense allows to easily extract ortho-view from the point-cloud and section to simplify the 3D modelling phase. At this stage different consideration need to be underline between the two buildings under analysis. The Smistamento Roundhouse is an industrial building with a modular structures and simple shape. In this case an automatization in the realization of the HBIM model was followed especially in the part of the internal structure. According to the modularity of the structure, the different pillars and beams were modelled according to the available scan data and copy in the other part of the building (Figure 9).

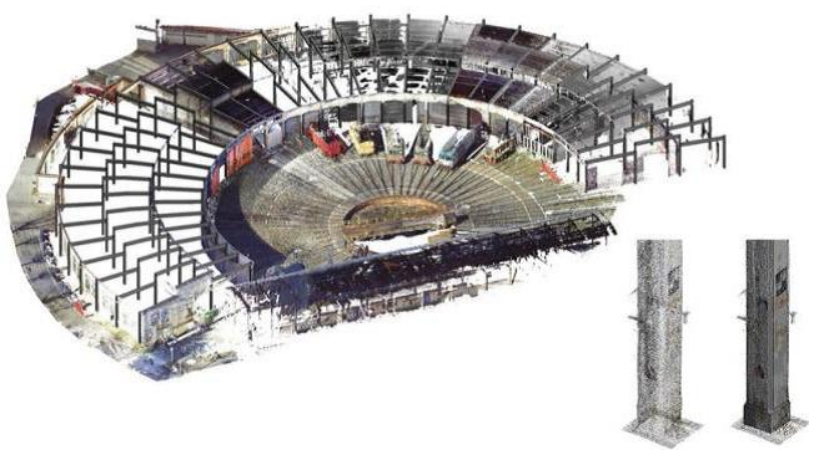

Figure 9. Overlapping between the structural system of beams and pillars and the total point cloud

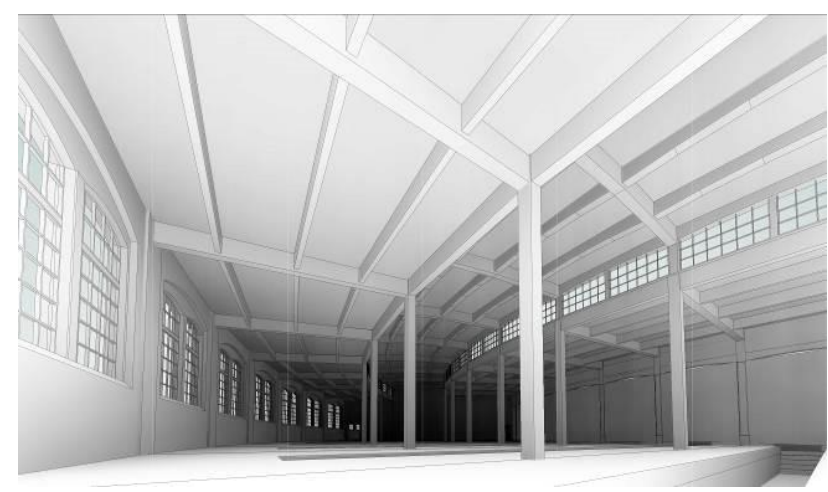

Figure 10. Internal perspective view of Smistamento Roundhouse

Finally, in order to check the geometric accuracy of the virtual model, a comparison between the used point cloud and the parametric achieved model has been performed, using the tool available in the used PointSense plug-in (Figure 11).
Different approaches were followed for the modelling phase of Palazzo Sarmatoris, since the shape of the object was more complex, especially in the internal rooms where different vaults with unconventional geometries were modelled.

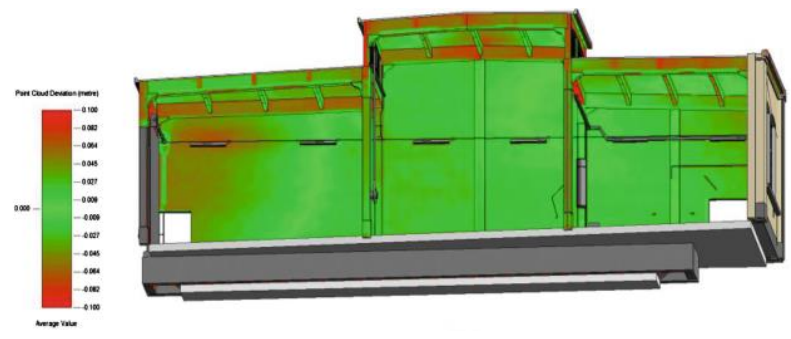

Figure 11. Discrepancy between the point cloud and parametric model. (most of the points that belong to the surface of the walls have a deviation that does not exceed $3 \mathrm{~cm}$ ).

The first approach allows to achieve the model according to the measures extracted from the photogrammetric model: the generator lines were used to realize the final 3D representation. The second approach refers to the generation of adaptive parametric models using the measurements derived by a direct survey: therefore, not all the internal parts were surveyed with a photogrammetric approach (Figure 12).
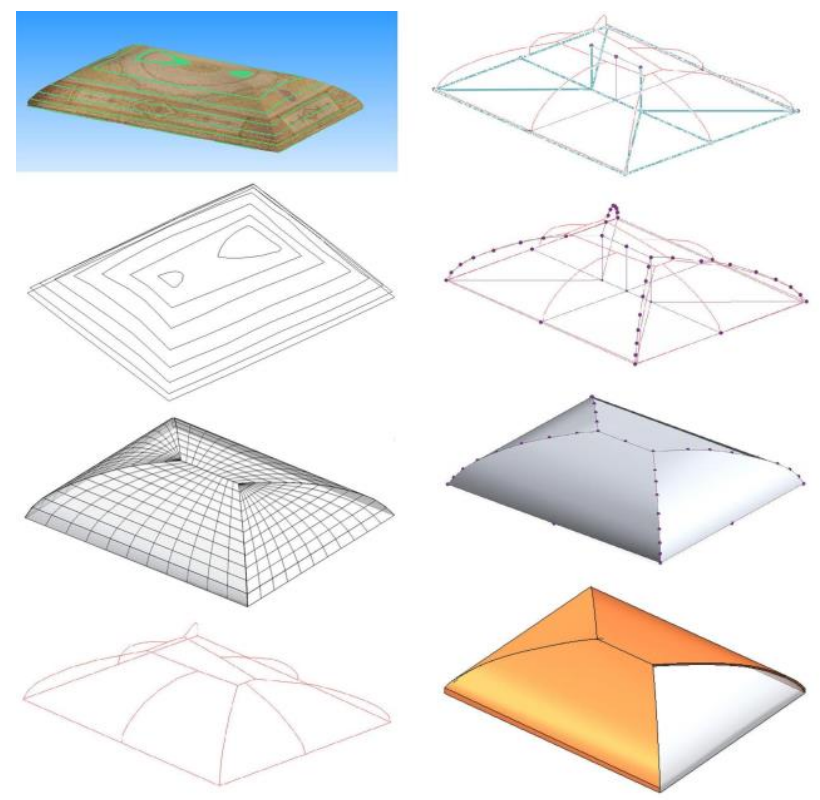

Figure 12. From the point cloud (upper left) to the re-topology and generator lines extraction. The mathematical is therefore converted in BIM model merging the "floor" component to the nails that allow to realize the pavilion vault.

The external part was modeled using the employed plug-in (Figure 12): the simple geometry of the façade allows to successfully use the semi-automatic approach. Finally, the roof was modelled using PointSense. Actually, the roof is simplified because the final representation does not consider the real shape of the covering surface (realized in tiles) but a simplification with a unique surface without any $3 \mathrm{D}$ shingles.

The final part of the research was connected to the data enrichment focused on the decay analysis. The aim is to design new strategies that can take advantage of the benefits of BIM also for less conventional activities: the decays have no specific building categories. However, the traditional orthogonal 
representation characterized by $2 \mathrm{D}$ patterns can't be semantically enriched by any parameter. This is the reason why the possibility of mapping in 3D the decay analysis was examined in detail.

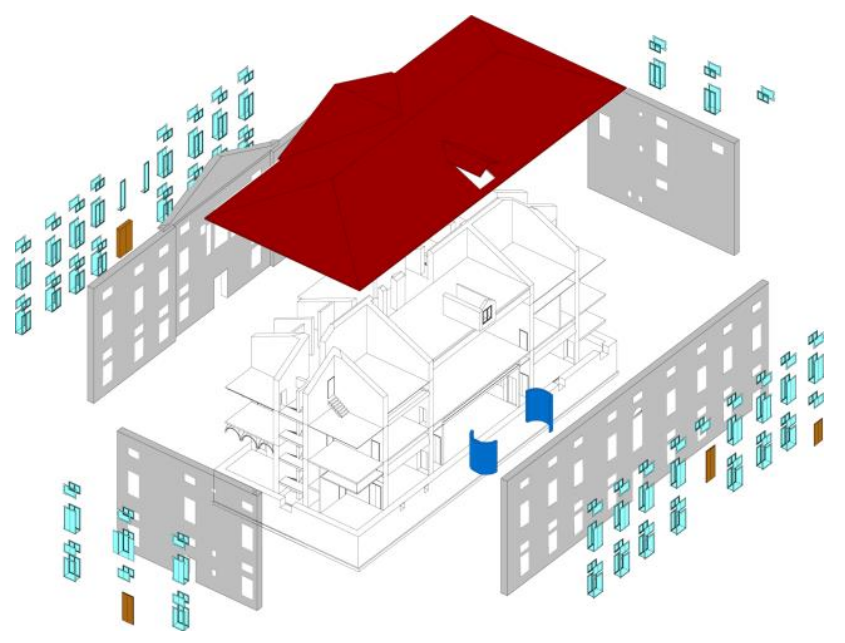

Figure 13. Exploded axonometry of the final parametric model realized for the Palazzo Sarmatoris.

\section{HBIM USED FOR RESTORATION PROCESS}

As reported before, the graphic representation of pathologies is very complex to be managed within the BIM environment; at this regard, a simple way can be related to the realization of thematic maps according to the available data that belong to the photogrammetric or TLS survey integrated in the BIM software.

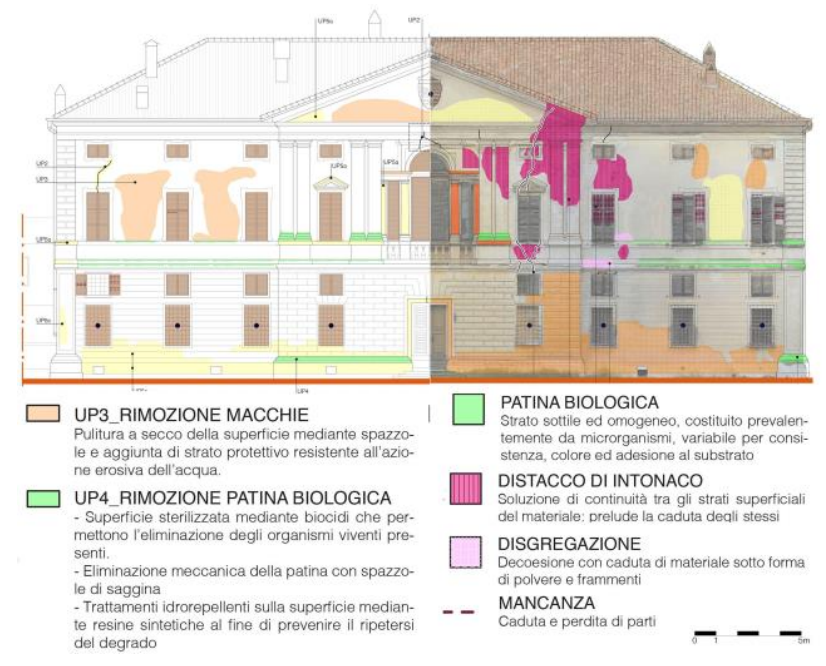

Figure 14. Decay analysis of a Palazzo Sarmatoris part generated in the HBIM software.

However, 3D modeling of decays in the BIM platform ensures to enrich the related database with graphic, geometric and alphanumeric data that can be effectively used to design and manage future interventions. The added value consists in its capability to associate new parameters that describe both the state of conservation of the materials and the detailed description of interventions needed to restore the building (Figure 14). In order to do that, the use an adaptive component was proposed: it is a particular object that can be adapted to a surface using movable vertex; as a consequence of that, this flexible geometry could be associated with flat and curved surfaces as well. The final part of the research project was connected to the graphic representation of the current conditions of the structure. This phase is quite new if compared to the available literature. This method has been applied to a significant portion of the construction in terms of the complexity of damage and its interaction with the context. The state of conservation, primitively recorded through traditional representation techniques, is based upon an updated method that has as a partial point of reference the Dalla Costa graphical method of abscissas and ordinates (Dalla Costa, 2000), along with the language illustrated in the UNI 11182-2006 standard (UNI, 2006), pairing color graphic icons (appropriately adjusted according to the basic architectural representation) to the thematic nature, and linked to a legend. Certain adjustments have been calibrated for the insertion of alphanumeric and graphic data in the parametric modelling environment. Upon second analysis, an adaptive component connectable to planar or curved surfaces has been added. In this way, the vertex may be modified and the thematic nature components such as decays and cracks are made visible in a 3D environment (Figure 15), allowing new visualization and analysis modes. The added value is the possibility of linking additional parameters, which describe and highlight the damage, the cause-effect relationship, the preservation operations planned, photographic images, and the results of non-destructive in situ and lab investigations resulting in additional qualitative and quantitative data (areas of decay or restoration, expressed in surface measures etc.). The availability of this type of modelling may be tested through a number of criteria, and likewise may be implemented in time, in the scope of diachronic monitoring and control of the preventive and planned conservation objectives.

\section{CONCLUSIONS}

The use of BIM in restoration projects related to cultural assets safeguarded by the Codice Urbani ("Urbani code" for cultural heritage and landscape, Italian Decree-Law $n^{\circ}$ 42/2004) is currently under discussion by the Commission appointed by the MiBACT (Italian Ministry of cultural heritage, cultural activities, and tourism) legislation office, which must proceed to draft a Ministerial Decree. Furthermore, the new UNI 11337:2017 standard, defining the different LOD for restoration (UNI, 2017), has been recently published. According to this new revolution in the restoration standards for architectural documentation it is possible to state that the approach in the present research today allows to obtain high detailed model that fits the need for the knowledge with analysis of the architectural heritage. All the survey process has been carried out using well known and consolidated technologies and methods for data acquisition and processing subsequently managed in commercial software and plug-in for the parametric modeling phase.

Further analysis need to be searched in the potentiality of HBIM systems, connected with the possibility that the Database linked to the model could give for an improvement of knowledge. It is crucial to take all the advantages of those new systems, not only to understand which is the best way to transform a $3 \mathrm{D}$ point cloud into a "rigorous" parametric model.

Together with the further analysis to obtain a well-structured workflow, enriched by an integrated survey methodology, we are assisting to the first development of open-source platforms and to some new application and trends in the traditional survey operations, at the regard, the research needs to be focused on those aspects as well. The last developments in survey are nowadays connected to the use of low cost a portable LiDAR instruments and new methodology like SLAM (Simultaneously Location and Mapping) that are very promising: probably less accurate but very fruitful in terms of time for acquisition and processing, so perfect tools for HBIM purpose. 


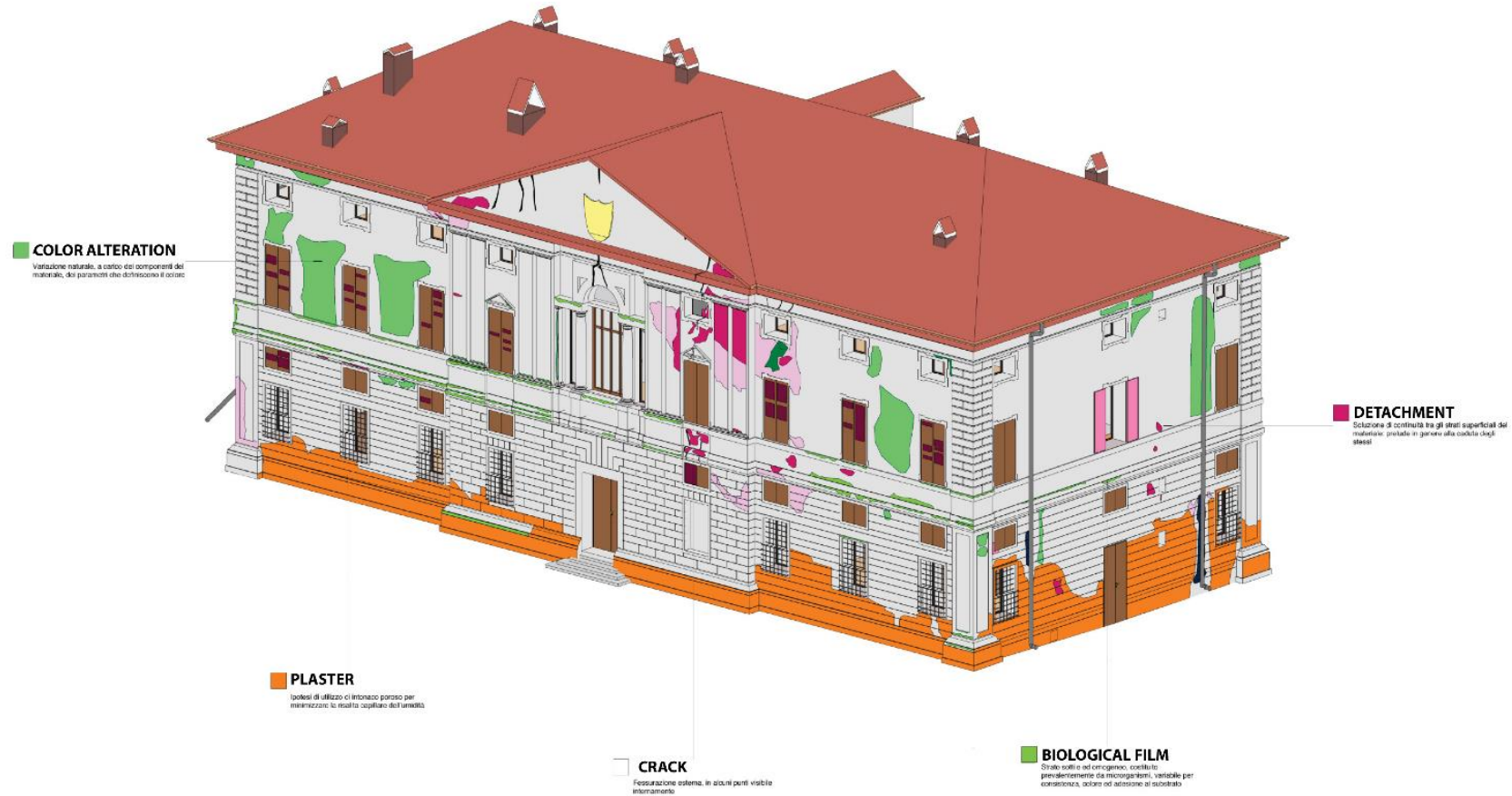

Figure 15. 3D visualization of the parametric model of Villa Sarmoris with the mapped decay.

Recent standard requirements immediately represent an acknowledgement of the widespread of BIM on a supranational level, especially due to its clear accordance with international standards and guidelines, which for years now have been compared to the delicate theme of the relationship between information content (graphic and alphanumeric) and construction process. An important goal for the next few years, (despite the market is still unprepared to implement such a massive revolution, especially in the Cultural Heritage field) is to embed in the system a very articulated computerized management. The presented examples require significant and demanding data acquisition and processing time, but unfortunately the professional's world has not those means. It is thus crucial that the research environment shall actively cooperate with the industrial sector to systemize the automation processes based on ontologies and semantic recognition of information. On the other hand, BIM management may truly represent the way of systemizing and thus filing a series of both referential and managerial data, which may be correlated and implemented as a critical support for the conservation process, from the restoration project/site "event" to the "duration" of the maintenance/conservation operations.

\section{ACKNOWLEDGMENTS}

The authors would like to thank especially F. Caputo, S. Farina, G.Fusaro and A. Galleano for the works and discussions on the HBIM. Another special thank goes to prof. Monica Naretto and Manuela Mattone for the important advices related to the restoration processes and the related representation methods conventionally used.

\section{REFERENCES}

AEC (UK), 2012. BIM Protocol. 1-46.

Apollonio F. I., Gaiani, M., Sun, Z. 2012. BIM-based modeling and data enrichment of classical architectural buildings. SCIRES-
IT 2(2), 41-62.

BSI, 2013. PAS 1192-2:2013 Specification for information management for the capital/delivery phase of construction projects using building information modelling.

BuildingSmart Finland, 2012. COBIM - Common BIM Requirements 2012, vol.1 - 12.

Barazzetti, L.; Banfi, F.; Brumana, R.; Gusmeroli, G.; Oreni, D.; Previtali, M.; Roncoroni, F.; Schiantarelli, G., 2015a. BIM From Laser Clouds and Finite Element Analysis: Combining Structural Analysis and Geometric Complexity. International Archives of the Photogrammetry, Remote Sensing and Spatial Information Sciences, Vol.XL-5/W4, pp. 345-350

Barazzetti, L., Banfi, F., Brumana, R., Oreni, D., Previtali, M., and Roncoroni, F., 2015b. HBIM and augmented information: towards a wider user community of image and range-based reconstructions, International Archives of the Photogrammetry, Remote Sensing and Spatial Information Sciences, Vol. XL5/W7, pp. 35-42

Biagini, C., Capone, P., Donato, V., Facchini N. 2016. Towards the BIM implementation for historical building restoration sites. Automation in Construction 71, 74-86.

Bonsma, P., Bonsma, I., Ziri, A. E., Parenti, S., Martín Lerones, P., Maietti, F., Medici, M., Turillazzi, B., Iadanza, E., 2016. INCEPTION Standard for Heritage BIM Models Digital Heritage. In: Progress in Cultural Heritage: Documentation, Preservation, and Protection, Springer International Publishing, pp. 590-599.

Castagnetti, C., Dubbini, M., Ricci, P. C., Rivola, R., Giannini, M., Capra, A., 2017.: Critical issues and key points from the survey to the creation of the Historical Building Information Model: the case of Santo Stefano Basilica. International Archives 
of the Photogrammetry, Remote Sensing and Spatial Information Sciences., Vol. XLII-5/W1, pp. 467-474.

Chiabrando, F., Spanò, A., 2013. Points Clouds generation using TLS and Dense-Matching techniques. A test on approachable accuracies of different tools. ISPRS Annals of the Photogrammetry, Remote Sensing and Spatial Information Sciences, II, pp. 2-6.

Chiabrando F., Lo Turco M., Santagati C., 2017. Digital invasions: from point clouds to historical building object modeling (H-BOM) of a Unesco WHL site. International Archives of the Photogrammetry, Remote Sensing and Spatial Information Sciences, pp. 171-178.

Dalla Costa, M. 2000. Il progetto di restauro per la conservazione del costruito, Celid, Turin.

Donato, V., Biagini, C., Bertini, G., and Marsugli, F., 2017. Challenges and opportunities for the implementation of H-BIM with regards to historical infrastructures: a case study of the ponte Giorgini in Castiglione della Pescaia (Grosseto - Italy), International Archives of the Photogrammetry, Remote Sensing and Spatial Information Sciences, Vol. XLII-5/W1, pp. 253-260.

Dore, C., Murphy, M., McCarthy, S., Brechin, F., Casidy, C., Dirix, E., 2015. Structural Simulations and Conservation Analysis-Historic Building Information Model (HBIM). International Archives of the Photogrammetry, Remote Sensing and Spatial Information Sciences. 3D Virtual Reconstruction and Visualization of Complex Architectures, 25-27 February 2015, Avila, Spain.

Eastman C., Teicholz P., Sacks R., Liston K., 2011. BIM Handbook: A Guide to Building Information Modeling for Owners, Managers, Designers, Engineers and Contractors. $2^{\circ}$ Edition. doi: 10.1002/9780470261309

Garagnani S., Manferdini M., 2013. Parametric accuracy: building information modeling process applied to the cultural heritage preservation, Int. Arch. Photogramm. Remote Sens. Spatial Inf. Sci. XL(5/W1), 87-92.

Hichri, N., Stefani, C., De Luca, L., Veron, P., Hamonet, G., 2013. From Point Cloud To BIM: a Survey of Existing Approaches. International Archives of the Photogrammetry, Remote Sensing and Spatial Information Sciences, XL-5/W2, pp. 343-348.

Inzerillo, L., Santagati, C., 2013. Using dense stereo matching techniques in survey. Disegnare Idee Immagini, 47/2013, pp. 82-91.

Kersten, T., Lindstaedt, M., 2012. Automatic 3D object reconstruction from multiple images for architectural, cultural heritage and archaeological applications using open-source software and web services, Photogramm. Fernerkundung Geoinf. 2012(6), 727-740.

Lin, Y. C. (2014). Construction 3D BIM-based knowledge management system: a case study. Journal of Civil Engineering and Management,20(2), 186-200.

Lo Buglio, D., De Luca, L. 2012. Representation of architectural artifacts: definition of an approach combining the complexity of the $3 \mathrm{~d}$ digital instance with the intelligibility of the theoretical model. SCIRES-IT SCIentific RESearch and Information Technology, Vol 2, Issue 2, 63-76.
Lo Turco, M., Mattone, M., Rinaudo, F. 2017. Metric survey and BIM technologies to record decay conditions. International Archives of the Photogrammetry, Remote Sensing and Spatial Information Science, vol. XLII-5 n. W1, pp. 261-268.

Lo Turco M., Sanna M., 2010a. La modellazione digitale ricostruttiva: il caso della chiesa della Misericordia a Torino. Disegnare Idee Immagini, Volume 21, Issue 41, December 2010, pp. 42-51.

Ludwig, M., Herbst, G., Rieke-Zapp, D., Rosenbauer, R., Rutishauser, S., Zellweger, A., 2013. The advantages of parametric modeling for the reconstruction of historic buildings. The example of the in war destroyed church of St. Catherine (Katharinenkirche) in Nuremberg. International Archives of the Photogrammetry, Remote Sensing and Spatial Information Sciences, Volume XL-5/W1, 2013 3D-ARCH 2013, pp. 25 - 26.

Miller, C., Thomas, D., Irigoyen, S. D., Hersberger, C., Nagy, Z., Rossi, D., Schlueter, A., 2014. BIM-extracted EnergyPlus model calibration for retrofit analysis of a historically listed building in Switzerland. Proceedings of SimBuild.

Murphy, M., McGovern, E., Pavia, S., 2013. Historic Building Information Modelling - Adding intelligence to laser and image based surveys of European classical architecture. ISPRS J Photogramm Remote Sens, 76, pp. 89-102.

Oreni D., Brumana R., Della Torre S., Banfi F., Barazzetti L., Previtali M, 2014. Survey turned into HBIM: the restoration and the work involved concerning the Basilica di Collemaggio after the earthquake (L'Aquila). International Archives of the Photogrammetry, Remote Sensing and Spatial Information Sciences, Volume II-5, ISPRS Technical Commission V Symposium, 23 - 25 June 2014, Riva del Garda, Italy.

Quattrini, R., Malinverni, E. S., Clini, P., Nespeca, R., Orlietti, E., 2015. From TLS to HBIM: high quality semantically-aware 3D modeling of complex architecture. International Archives of the Photogrammetry, Remote Sensing and Spatial Information Sciences, 40(5/W4), pp. 367-374.

Roccia, R., 2000. Theatrum Sabaudiae: teatro degli Stati del Duca di Savoia, Archivio Storico della Città di Torino, Collana Blu, Torino.

Santagati, C., Lo Turco, M., 2016. From structure from motion to historical building information modeling: populating a semantic-aware library of architectural elements. J. Electron. Imaging 26(1), 011007.

Statsbygg, 2013. Statsbygg BIM Manual Version 1.2.1. 1:1-98.

Tang, P. Huber, D., Akinci B. Lipman, R. Lytle, A. 2010. Automatic reconstruction of as-built building information models from laser-scanned point clouds: a review of related techniques, Autom. Constr. 19, pp.829-843.

UNI 11182:2006. Beni culturali - Materiali lapidei naturali ed artificiali - Descrizione della forma di alterazione - Termini e definizioni.

UNI 11337:2017. Edilizia e opere di ingegneria civile - Gestione digitale dei processi informativi.

Volk, R.; Stengel, J.; Schultmann, F. 2014. Building Information Models (BIM) for existing buildings - literature review and future needs. Automation in Construction 38, pp.109-127. 